\title{
Short communication Does presurgical treatment destroy important prognostic information
}

\author{
J Michael Dixon
}

Edinburgh Breast Unit, Western General Hospital, Edinburgh, EH4 2XU, UK

Corresponding author: J Michael Dixon, jmd@ed.ac.uk

Published: 20 December 2007

This article is online at http://breast-cancer-research.com/content/9/S2/S17 (c) 2007 BioMed Central Ltd
Breast Cancer Research 2007, 9(Suppl 2):S17 (doi:10.1186/bcr1815)

assessed by imaging. Studies have shown that ultrasound [2] and magnetic resonance imaging (MRI) [3] can accurately assess tumour size. These modalities can also be used to assess response, and all patients receiving neoadjuvant therapy should have preoperative ultrasound and many will have MRI. Even in the absence of an accurate measure of tumour size by the pathologist using imaging at diagnosis, it should thus be possible in most patients to gain an accurate assessment of initial tumour size. Studies have also shown that, even after neoadjuvant endocrine therapy, baseline tumour size correlates with breast cancer specific outcome despite the intervening neoadjuvant therapy [4].

\section{Node status}

Node status at diagnosis can be assessed using imaging together with fine needle aspiration (FNA), cytology, or core biopsy of any suspicious nodes. Using this combination of tests it is possible to identify approximately $50 \%$ of patients with involved nodes, but importantly it does identify the majority of patients with multiple involved nodes [5]. Some assessment of axillary lymph node status is thus possible even in patients receiving neoadjuvant therapy. There is evidence in the literature that patients, particularly after neoadjuvant chemotherapy, change their node status and patients who were previously node positive become node negative [6]. Such patients have an improved prognosis, particularly if the sterilization of the nodes is combined with a complete response within the breast. For patients who come to surgery after a course of neoadjuvant therapy, node status at that time remains a highly significant indicator of prognosis, whether this is after neoadjuvant chemotherapy or after neoadjuvant endocrine therapy.

\section{Tumour grade}

Histological grade can be assessed on the initial diagnostic core biopsy. Studies that have correlated grade on core biopsy with a subsequent grade at surgery show that it is accurate in about $60 \%$ of tumours [7]. Grade does change with both short courses and neoadjuvant treatment, and there

subsequent surgery is likely to differ significantly from th initial tumour size. Tumour size at diagnosis can, however, be 
is some evidence in the neoadjuvant setting that cancers that downgrade have a better response and long-term outlook [8].

\section{Oestrogen receptor status}

Both ER and progesterone receptor status are best assessed on the initial diagnostic core biopsy at diagnosis, because of the rapid penetration of fixative into such small specimens. Information on hormone receptor status is thus not influenced by presurgical therapy.

\section{HER2 status}

Although not incorporated into the currently used prognostic indices, the HER2 status of the tumour does predict patient outcome and can be measured accurately on the initial core biopsy. It is thus available for all patients receiving preoperative therapy, and an assessment of HER2 status is currently used to determine whether patients should be given chemotherapy alone or preoperative chemotherapy combined with trastuzumab.

\section{Newer prognostic factors}

Studies have shown that gene profiling of the tumour at diagnosis correlates with long-term outcome [1]. It is possible to carry out such studies on the initial core biopsy. Hence, whether the patient is treated with surgery initially or receives presurgical therapy, baseline gene profiling can be available if fresh tissue is stored at the time of the initial diagnostic core biopsy.

\section{Prognostic factors in patients undergoing neoadjuvant therapy}

One potential advantage of neoadjuvant therapy is that as a consequence of the treatment more information on the tumour is obtained and this information itself has prognostic value.

\section{Response to treatment}

Histological response after neoadjuvant chemotherapy has important prognostic implications. Patients who have a complete pathological response have a much better outlook than do patients who still have residual tumour after therapy [6].

\section{Biological measurements}

The degree of proliferation as measured by Ki67 in a tumour at diagnosis has been identified as a predictive factor on univariate analysis, but proliferation often fails to maintain its independent significance on multivariate analysis because tumour grade already incorporates an assessment of the mitotic rate. Following neoadjuvant therapy it is possible to assess both the change and the level of residual proliferation. Studies have shown that after neoadjuvant endocrine therapy, there are rapid falls in proliferation shortly after treatment has started $[9,10]$. After these rapid falls, the majority of cancers maintain this fall, although in some cancers by 3 months the proliferation rises close to baseline levels [10]. A number of studies have shown that both the percentage reduction in proliferation and the level of residual proliferation after treatment are powerful prognostic factors, both for local recurrence and subsequent breast cancer specific survival $[4,10]$.

\section{Changes in gene expression during treatment}

There have been no studies carried out of changes in gene expression and correlation with outcomes after chemotherapy, but studies have been conducted in patients treated with neoadjuvant letrozole [11]. One of these studies correlated gene expression at baseline, after 2 weeks and changes during the first 2 weeks of therapy with subsequent response. This study has shown that although some baseline and day 14 gene expression profiles do correlate with response, the most accurate predictors of response are changes in gene expression. Those tumours that did respond had a consistent pattern of gene expression change. In contrast, those tumours that were resistant to therapy exhibited a variety of patterns. There thus appears to be a consistent signature for response to endocrine therapy but a diverse signature for resistance [12].

\section{Discussion}

From the evidence presented, many of the factors that are currently used to estimate prognosis can be measured or estimated even in patients undergoing neoadjuvant therapy. Changes within the tumour that occur as a consequence of the therapy also have prognostic significance. There is thus a greater amount of information available to predict prognosis in patients who undergo neoadjuvant chemotherapy than in patients who have surgery as their initial treatment. The National Surgical Adjuvant Breast and Bowel Project (NSABP) study of preoperative versus postoperative chemotherapy showed that although it is true that different factors predicted outcome in the neoadjuvant group, the outcomes for each decile of patients as calculated using prognostic factors was identical [6]. Thus, the top $10 \%$ of patients as predicted by the prognostic factors receiving neoadjuvant chemotherapy had an identical outcome to the top $10 \%$ in the adjuvant group. In other words, whether the patients had neoadjuvant therapy or not did not influence the ability to predict survival. The conclusion must therefore be that whatever neoadjuvant therapy does to the cancer, it does not improve or reduce our ability to predict prognosis.

There is increasing emphasis on measuring gene expression. It may be possible in the future to treat patients with a short course of presurgical treatment and, by analyzing the changes in the tumour that occur as a consequence of treatment, to determine the effectiveness of the treatment (and thus how an individual patient's cancer should be treated) but also to gain prognostic information on long-term outcome. One problem with the current tools for prognosis is that they provide information on the percentage chance of a group of women with a particular type of tumour being alive and disease free, but they are of little value in the individual 
patient. It is for this reason that further studies of the dynamic changes in individual patients that occur as a result of therapy continue to be investigated.

\section{Acknowledgement}

This article has been published as part of Breast Cancer Research Volume 9 Supplement 2, 2007: Controversies in Breast Cancer. The full contents of the supplement are available online at http://breastcancer-research.com/supplements/9/S2.

\section{References}

1. Thompson AM, Pinder SE: From prognostic factors. In $A B C$ of Breast Diseases, 3rd ed. Edited by Dixon JM. Oxford, UK: Blackwell Publishing; 2006:77-80.

2. Shoma A, Moutamed A, Ameen M, Abdelwahab A: Ultrasound for accurate measurement of invasive breast cancer tumor size. Breast J 2006, 12:252-256.

3. Orel SG: From imaging analysis: magnetic resonance imaging. In Diseases of the Breast, 3rd ed. Edited by Harris JR, Lippman ME, Morrow M, Osborne CK. Philadelphia, PA: Lippincott Williams \& Wilkins; 2004:165-180.

4. Murray E, Renshaw L, Macaskill EJ, Murray J, McCaig F, Young O, Cameron D, Kerr G, Thomas JS, Jack W, Dixon JM: Factors predicting survival after neoadjuvant therapy with aromatase inhibitors [abstract]. Breast Cancer Res Treat 2006, 100:s23.

5. Ciatto $S$, Brancato $B$, Risso G, Ambrogetti D, Bulgaresi $P$, Maddau C, Turco P, Houssami N: Accuracy of fine needle aspiration cytology (FNAC) of axillary lymph nodes as a triage test in breast cancer staging. Breast Cancer Res Treat 2007, 103: 85-91.

6. Fisher B, Bryant J, Wolmark N, Mamounas E, Brown A, Fisher ER,
Wickerham DL, Begovic M, DeCillis A, Robidoux A, et al.: Effect of preoperative chemotherapy on the outcome of women with operable breast cancer. J Clin Oncol 1998, 16:2672-2685.

7. O'Leary R, Hawkins K, Beazley JC, Lansdown MR, Hanby AM: Agreement between preoperative core needle biopsy and postoperative invasive breast cancer histopathology is not dependent on the amount of clinical material obtained. $J$ Clin Pathol 2004, 57:193-195.

8. Dani M, McDonnell J, Karp S, Jaffe V: Do breast cancer tumours downsize as well as downgrade with neoadjuvant chemotherapy? Breast Cancer Res 2007, 9(suppl 3):P3.

9. Smith IE, Dowsett M, Ebbs SR, Dixon JM, Skene A, Blohmer JU, Ashley SE, Francis S, Boeddinghaus I, Walsh G; IMPACT Trialists Group: Neoadjuvant treatment of postmenopausal breast cancer with anastrozole, tamoxifen, or both in combination: the immediate preoperative anastrozole, tamoxifen, or combined with tamoxifen (IMPACT) multicenter double blind randomized trial. J Clin Pathol 2005, 23:5108-5116.

10. Dowsett M, Smith IE, Ebbs SR, Dixon JM, Skene A, A'Hern R, Salter J, Detre S, Hills M, Walsh G; IMPACT Trialists Group: Prognostic value of Ki67 expression after short-term presurgical endocrine therapy for primary breast cancer. J Natl Cancer Inst 2007, 99:167-170.

11. Miller WR, Larionov AA, Renshaw L, Anderson TJ, White S, Murray J, Murray E, Hampton G, Walker JR, Ho S, et al.: Changes in breast cancer transcriptional profiles after treatment with the aromatase inhibitor letrozole. Pharmacogenet Genomics 2007, 17:813-826.

12. Miller WR, Krause A, Evans DB, Renshaw L, Murray J, Larionov A, Anderson TJ, White S, Hampton G, Walker JR, et al.: Phenotypes for endocrine resistance can be identified by RNA microarray of sequential biopsies and are more variable than those predicting for tumour response [abstract]. Breast Cancer Res Treat 2005, 94:s17. 